\title{
Development of image analysis using Python: Relationship between matrix ratio of composite resin and curing temperature
}

\author{
Miki HORI ${ }^{1,2}$, Kotaro FUJIMOTO'1, Tadasuke HORI², Hironao SEKINE², Atsuko UENO2,3, Akiko KATO4 \\ and Tatsushi KAWAI1,2 \\ ${ }^{1}$ Department of Dental Materials Science, School of Dentistry, Aichi Gakuin University, 1-100 Kusumoto-cho, Chikusa-ku, Nagoya, Aichi 464-8650, \\ Japan \\ ${ }^{2}$ Center for Advanced Oral Science, School of Dentistry, Aichi Gakuin University, 1-100 Kusumoto-cho, Chikusa-ku, Nagoya, Aichi 464-8650, Japan \\ ${ }^{3}$ Department of Gerodontology, School of Dentistry, Aichi Gakuin University, 1-100 Kusumoto-cho, Chikusa-ku, Nagoya, Aichi 464-8650, Japan \\ ${ }^{4}$ Department of Oral Anatomy, School of Dentistry, Aichi Gakuin University, 1-100 Kusumoto-cho, Chikusa-ku, Nagoya, Aichi 464-8650, Japan \\ Corresponding author, Miki HORl; E-mail: mikihori@dpc.agu.ac.jp
}

The aim of this study was to establish a measurement method for filler and matrix in cured resin composite (RC) using Python programming and to investigate the correlation between matrix ratio and curing temperature rise. Eight kinds of RCs were used. Backscattered electron images were taken for each cured specimen. Matrix and filler contents were calculated using Python programming with the K-means or area segmentation method. Volume measurement methods were assessed for comparison. Heat released during the polymerization reaction was measured. The matrix ratio was calculated without human intervention. Three specimens contained only inorganic filler, and other specimens contained multiple types of fillers. Almost the same values of the matrix ratio were obtained by programming and the volume measurement methods for specimens containing a single type of inorganic filler. Moreover, a strong correlation was found between the matrix ratio obtained by the programming method and curing temperature rise $(\mathrm{R}=0.9826)$.

Keywords: Python programming, Composite resin, Segmentation analysis, Temperature rise, Correlation analysis

\section{INTRODUCTION}

Resin composite (RC) is routinely used as a dental restorative material in clinical practice, but the influence of heat released during the polymerization reaction has been reported to be a concern ${ }^{1-3)}$. Factors affecting the amount of heat released include thermal energy from the light source and the heat of polymerization. In particular, it is important to know the quantitative ratio of monomers involved in the polymerization reaction, because the amount of $\mathrm{C}=\mathrm{C}$ double bond has a direct bearing on the exothermicity of the polymerization. In an ISO standard ${ }^{4}$, the ash method has been introduced as a measurement method for the ratio between inorganic and organic materials in RCs. However, the mixing ratio of inorganic and organic components is modified for esthetics ${ }^{5-7)}$ or toughness ${ }^{8,9)}$. Some RCs used based on esthetics considerations are blends of organic fillers for reducing the amount of monomer. Therefore, the ratio of filler components in such RCs cannot be determined by the ash method. Many methods have been developed for determining the components of RC. Some papers have introduced methods for estimating the filler content from numerical measurements of physical quantities, such as amounts separated by elution, Poisson's ratio ${ }^{10}$, rheological properties ${ }^{11)}$, and elastic properties ${ }^{12)}$. These methods require a large specimen, so measurements are difficult for expensive or cured specimens. The aim of this study was to establish a measurement method for filler and matrix from cross-sections of cured RC using programming. Establishing this new method is expected to facilitate prediction of various physical properties of $\mathrm{RCs}$ such as heat generation during polymerization.

Images are routinely used for both assessment in research and diagnosis in clinical practice. Various software packages are available for image processing, such as Image ${ }^{13}$ ). Although these software packages can detect specific colors or adjust image contrast density using data possessing, the parts to be identified still require manual operations ${ }^{14)}$. Such work tends to differ between individuals and is usually time-consuming.

Recently, the open source programming language Python has attracted growing attention ${ }^{15}$. Python might be a suitable language for development because it is easy to use, has a good graphical user interface, and has many modules that are publicly available via the internet, including ones for mathematical processing ${ }^{16}$ and graphical processing ${ }^{17,18}$.

This study examines the hypothesis that the matrix ratio of $\mathrm{RC}$ can be calculated from cross-sectional images without human intervention.

\section{MATERIALS AND METHODS}

The manufacturers and compositions of the tested RCs are presented in Table 1 .

Color figures can be viewed in the online issue, which is available at J-STAGE.

Received Jun 3, 2019: Accepted Sep 2, 2019

doi:10.4012/dmj.2019-163 JOI JST.JSTAGE/dmj/2019-163 
Table 1 Compositions and manufacturers of the materials used in the study

\begin{tabular}{|c|c|c|c|c|}
\hline Material & Abbreviation & Туре & Manufacturer & Composition \\
\hline SOLARE & Sol & Paste & GC, Tokyo, Japan & Fluoroaluminosilicate, UDMA \\
\hline SOLARE P & SolP & Paste & $\mathrm{GC}$ & Fluoroaluminosilicate, UDMA \\
\hline $\begin{array}{l}\text { Spectrum } \\
\text { TPH3 Compule }\end{array}$ & $\mathrm{TPH}$ & Paste & $\begin{array}{l}\text { Dentsply DeTrey, } \\
\text { Konstanz, Germany }\end{array}$ & $\begin{array}{l}\text { Glass wool, lead bisilicate, bisphenol A } \\
\text { ethoxylate dimethacrylate, TEGDMA, } \\
\text { EBPADMA Uletan resin, fumed silica } \\
\text { amorphous, } \mathrm{TiO}_{2}\end{array}$ \\
\hline Unifil Flow & $\mathrm{UF}$ & Flowable & GC & Fluoroaluminosilicate, UDMA \\
\hline $\begin{array}{l}\text { Clearfil } \\
\text { Majesty ES }\end{array}$ & Maj & Flowable & $\begin{array}{l}\text { Kuraray Noritake Dental, } \\
\text { Tokyo, Japan }\end{array}$ & $\begin{array}{l}\text { Surface-treatment of barium glass filler, } \\
\text { Surface-treatment of silica filler, TEGDMA }\end{array}$ \\
\hline Prime Fil & $\mathrm{PF}$ & Flowable & $\begin{array}{l}\text { Tokuyama Dental, Tokyo, } \\
\text { Japan }\end{array}$ & $\begin{array}{l}\text { Inorganic filler (silica, zirconia), } \\
\text { TEGDMA, Bis-MPEPP, Bis-GMA }\end{array}$ \\
\hline $\begin{array}{l}\text { Filtek } \\
\text { Supreme Ultra }\end{array}$ & Sup & Flowable & $\begin{array}{l}\text { 3M ESPE, St Paul, } \\
\text { MN, USA }\end{array}$ & Bis-GMA,TEGDMA, inorganic filler \\
\hline $\begin{array}{l}\text { Revolution } \\
\text { Formula2 }\end{array}$ & Rev & Flowable & Kerr, Orange, CA, USA & $\begin{array}{l}\text { Bis-GMA, bisphenol A ethoxylate } \\
\text { dimethacrylate, barium alminoborosilicate } \\
\text { glass, Silica }\end{array}$ \\
\hline
\end{tabular}

Compositions according to the manufacturer are shown.

UDMA, urethane dimethacrylate; TEGDMA: triethyleneglycol dimethacrylate; EBPADMA: ethoxylated bisphenol A dimethacrylate; Bis-MPEPP: 2,2'-bis (4-methacryloxy polyethoxyphenyl) propane; Bis-GMA: bisphenol A-glycidyl methacrylate.

\section{Image observation}

RC specimens (A3 shade), $1 \mathrm{~mm}$ in thickness and $5 \mathrm{~mm}$ in diameter, were fabricated using Teflon molds. The specimens were light-cured following the manufacturer's instructions using an LED curing light device (VALO, Ultradent Products, South Jordan, UT, USA). The curing tip was positioned perpendicular to the specimen surface. The power output density used was 1,000 $\mathrm{mW} / \mathrm{cm}^{2}$. Specimens were mounted in an Epofix resin (Strueres, Ballerup, Denmark), and cross-sections were polished using abrasive paper with grit of P280. The sectioned surfaces were further polished using wet abrasive paper (up to P5000) and then polished using 5-, 1-, and $0.3-\mu \mathrm{m}$ alumina polishing compounds. The specimen was rinsed with water and ultrasonicated in $100 \%$ ethanol for $5 \mathrm{~min}$ three times and air-dried with an aspirator for $30 \mathrm{~min}$. Surfaces of all specimens were sputter-coated with carbon to provide electrical conductivity. Elemental analysis was performed using a field-emission electron probe micro analyzer (JXA8530FA, JEOL, Tokyo, Japan). The probe was operated at an accelerating voltage of $10 \mathrm{kV}$ and a probe current of $50 \mathrm{nA}$. Backscattered electron (BSE) images were acquired to obtain Z-contrast images. Micrographs were recorded with magnification of $400 \times, 1,000 \times, 5,000 \times$, and $10,000 \times$.

\section{Image analysis by Python programming}

The structure of each specimen was analysis using a BSE image. The programming language used was Python. The development environment was as follows. The computer was an Apple MacBook Air with a $1.6 \mathrm{GHz}$ Intel Core 2 Duo processor and $4 \mathrm{~GB}$ of $1,067 \mathrm{MHz}$ DDR3 RAM. The operation system was Mac OS X Sierra 10.12.6. Python version 3.6.3 was used with various program module extensions, such as ones for image processing and batch data processing. Specifically, Tkinter was used as a basic module for the graphical user interface, the Python Image Library (PIL) was used for image processing capabilities, and Numpy was selected as a numerical extension module. K-means clustering was implemented using the K-means module ${ }^{19)}$ from the scikit-learn package. A flowchart of the image analysis program is shown in Fig. 1. The K-means algorithm starts from a random initial clustering, and then iteratively calculates the cluster centroids and reassigns elements to the cluster with the closest centroid. The algorithm halts when no more reassignments are made. It starts from an arbitrary seed point designated by random_state to enable reproducible data analysis. When the organic filler and matrix have the same color value, they cannot be separated by the $\mathrm{K}$-means method because they are classified as having the same attribute. Thus, as described below, the area segmentation method was implemented in a Python program to separate the organic filler and matrix. The flowchart of the area segmentation program is shown in Fig. 2. By setting an adequate threshold value, the gray level image can be converted to a binary image in which inorganic filler is segmented from the other materials. The threshold value for binarization was determined to be 140. Subsequently, as shown in Fig. 3, the pixels are determined one by one. Concretely speaking, if all pixels 


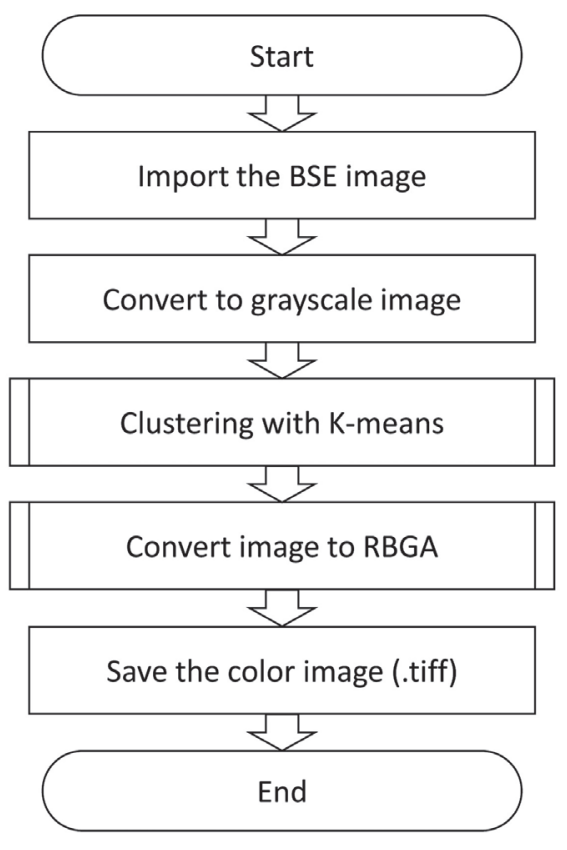

Fig. 1 Flowchart for the K-means clustering algorithm.

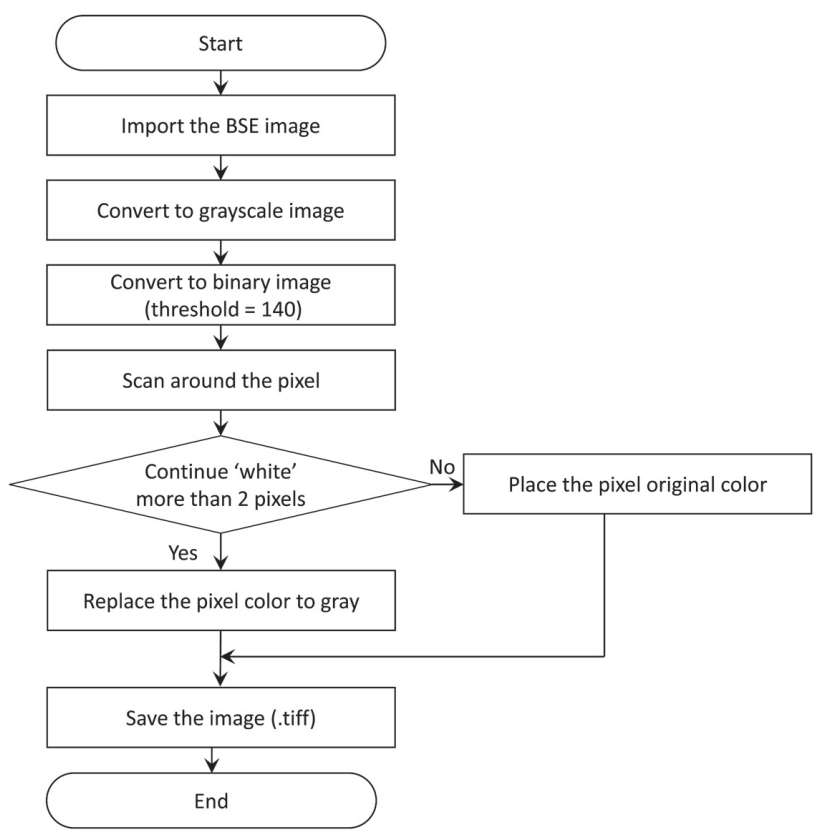

Fig. 2 Flowchart for the area segmentation program.

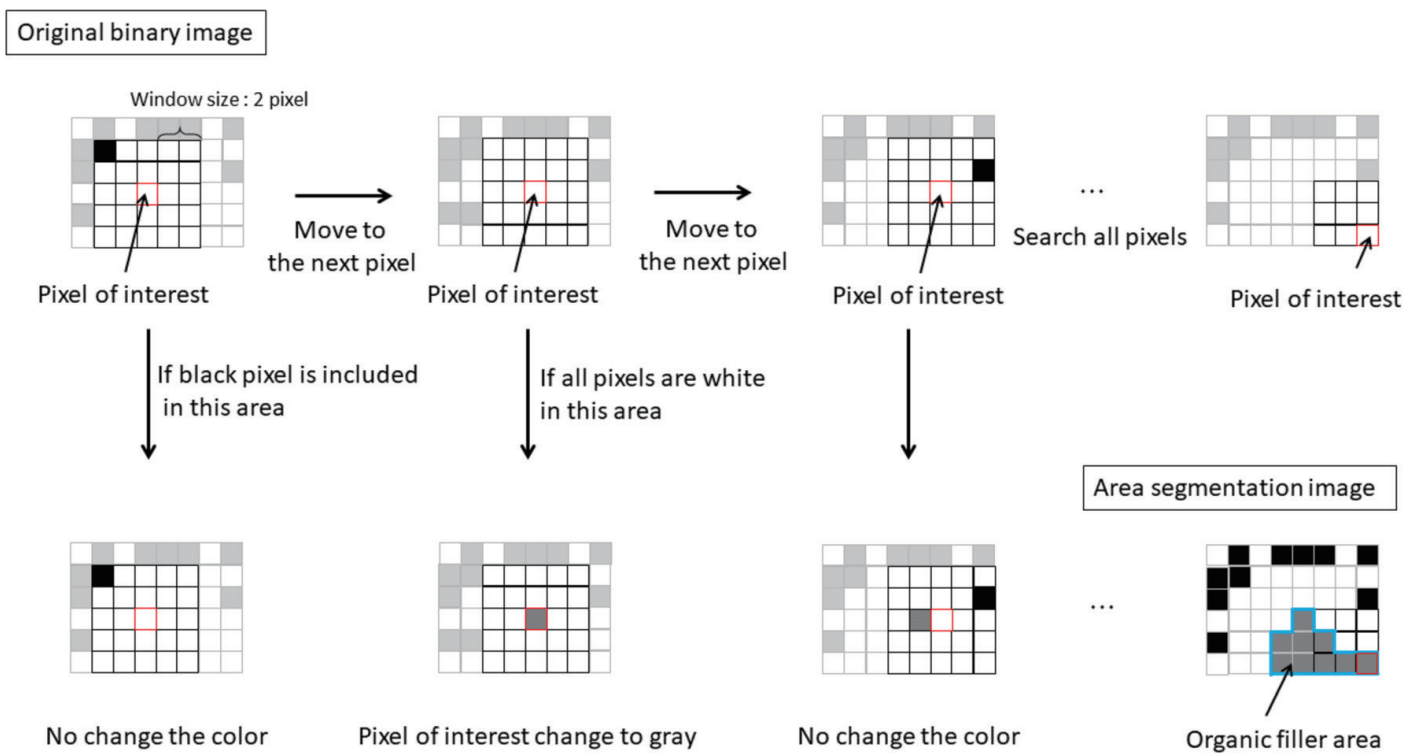

Fig. 3 Algorithm of the area segmentation method.

within a window size of 2 are white (color value: 255), which represents the organic region to be classified, the center pixel is transform to gray. If a black pixel is included in this area, the color is left as is. The abundance ratios of matrix and filler were calculated by counting the number of pixels with each color (black, gray and white). Five images were used for each specimen.

Measurement of organic materials volume

To determine the organic materials volume, inorganic and organic content (wt\%) was measured by the ash method and the filler density was measured using a liquid pycnometer. The organic materials volume was calculated using values obtained by each method.

To measure the weight percentage of inorganic fillers in the RCs, the standard ash method was used as described in ISO 1172:1996 ${ }^{20)}$. Each specimen (approximately $0.5 \mathrm{~g}, n=3$ ) was placed in an alumina crucible, and the weight of the specimen including the crucible was measured with a precision digital balance (CP225D, Sartorius, Goettingen, Germany; minimum reading: $0.01 \mathrm{mg})$. The crucible with the specimen 
was heated in an electric furnace (KDF S80, Denkenhighdental, Kyoto, Japan) at $550^{\circ} \mathrm{C}$ for $60 \mathrm{~min}$ to burn out the organic component. After cooling to ambient temperature in a desiccator, the residue and crucible were reweighed until a constant mass was obtained at two subsequent measurements. The organic materials content (wt\%) was determined using the following equation:

$$
m_{m}=\left\{1-\left(m_{3}-m_{1}\right) /\left(m_{2}-m_{1}\right)\right\} \times 100(\mathrm{wt} \%)
$$

where $m_{m}$ is the organic materials content (wt\%), $m_{1}$ is the initial mass of the dry crucible $(\mathrm{g}) ; m_{2}$ is the initial mass of the dry crucible plus the cured RC (g); and $m_{3}$ is the final mass of the crucible plus the residue after calcination $(\mathrm{g})$.

The density of each filler was measured with a liquid pycnometer using distilled water as the working fluid. Filler was used as obtained from the ash method. A 22mL pycnometer (Hubbard type, Sogo Laboratory Glass Works, Kyoto, Japan) was used. All measurements were performed at a constant temperature of $23 \pm 1^{\circ} \mathrm{C}$. First, the pycnometer plus stopper $\left(m_{\circ}\right)$ was weighted. The pycnometer was filled with distilled water and stoppered, and the pycnometer marks were aligned. Tiny air bubbles can be removed by immersing the flask into an ultrasonic cleaner for several seconds. After drying the outside of the pycnometer with lint-free wipes, the pycnometer plus stopper plus water was weighed $\left(m_{p f}\right)$. All fluid was removed, and the pycnometer and stopper were dried completely. Next, inorganic filler was put into the pycnometer and it was stoppered. The pycnometer plus inorganic filler plus stopper was weighed $\left(m_{s}\right)$. Water was then added into the pycnometer, and vacuum degassing was performed to dislodge air bubbles from the specimen. The pycnometer was then refilled with additional distilled water, the marks were aligned, and the outside of the pycnometer was dried. Then, the pycnometer plus stopper plus inorganic filler plus additional water was weighed $\left(m_{t}\right)$. The following equations were used to determine the density of the inorganic filler from the weight measurements:

$$
\begin{aligned}
& d_{f}=d_{w} \times\left(m_{s}-m_{o}\right) /\left(m_{p f}-m_{t}+m_{s}-m_{o}\right) \\
& d_{w}=-0.0003 t+1.0031
\end{aligned}
$$

where $d_{f}$ is density of the specimen $(\mathrm{g} / \mathrm{mL}), d_{w}$ is the density of water $(\mathrm{g} / \mathrm{mL})$ and $t$ is the temperature $\left({ }^{\circ} \mathrm{C}\right)$. A polyfunctional monomer was used as the organic material, and its density is about $1.2-1.3^{21)}$. The following equation was used to determine the matrix volume ratio from the mass and density of each material.

$$
V_{m}=\left\{m_{m} / d_{m}\right\} /\left\{\left(100-m_{m}\right) / d_{f}+m_{m} / d_{m}\right\} \times 100(\%)
$$

where $V_{m}$ is matrix volume ratio (\%) and $d_{m}$ is the density of the organic material $\left(\mathrm{g} / \mathrm{cm}^{3}\right)$.

Measurement of heat released during polymerization To measure the heat released during the polymerization reaction, a method previously reported by Hori et al. ${ }^{3)}$ was used to measure the heat released during the polymerization reaction. Each specimen was filled into a cylindrical white Teflon mold with an inner diameter of $5.0 \mathrm{~mm}$ and a depth of $1.0 \mathrm{~mm}$. A cover glass was placed at the bottom of the Teflon mold. Before polymerization of the $\mathrm{RC}$, a type $\mathrm{K}$ of thermocouple was positioned at the center of the uncovered surface of the RC by using a three-dimensional linear stage. The specimen was irradiated using an LED curing light device (VALO). Light-curing conditions were $10 \mathrm{~s}$ in standard mode with an output power of $1,000 \mathrm{~mW} \cdot \mathrm{cm}^{-2}$. The temperature change during light curing of a RC specimen was measured.

\section{Statistical analysis}

Results are expressed as the mean \pm standard deviation of each measurement. The matrix volume ratio of specimens containing a single kind of inorganic filler was compared between the programming method and volume measurement methods. The kinds of fillers contained in the RCs were determined from BSE images. Statistical differences were assessed by two-sided Student's $t$ test with $p<0.05$ considered to be significant.

\section{RESULTS}

Typical magnified BSE images used in image analysis are shown in Fig. 4. A complex structure was present in all specimens. Three specimens (Rev, Maj, and TPH) contained a single type of filler that exhibited the same color value. The other specimens contained multiple types of fillers. Among them, Sol and SolP were observed to contain a dispersion of organic filler with size greater than $20 \mu \mathrm{m}$ that had the same color value as the matrix. Six kinds of specimens were analyzed by the K-means method and the other two specimens (Sol and SolP) were analyzed by the area segmentation method. Processing using the K-means method took a mean time of $1.5 \mathrm{~min}$ per image, and the area segmentation method took a mean time of $3 \mathrm{~min}$ and $10 \mathrm{~s}$ per image. Results for the matrix area ratio obtained by the programming method, density of the fillers used in calculating matrix volume ratio, the matrix volume ratio, and the maximum temperature measured during the curing process are shown in Table 2. Comparing the matrix volume ratios to the matrix area ratios obtained from programming, no significant difference was found for UF, Maj, and Rev. However, disagreement of approximately 4\% between the programming and volume measurement methods was found for TPH, which contains only a single inorganic filler). The other specimens containing organic filler had completely different results for the matrix abundance ratio between the programming and volume measurement method.

As shown by the programming method, the matrix ratio of paste-type resin tended to be less than that of flowable-type resin. In addition, the mean maximum temperature followed a similar trend. The maximum temperature relatively subdued for all paste-type 

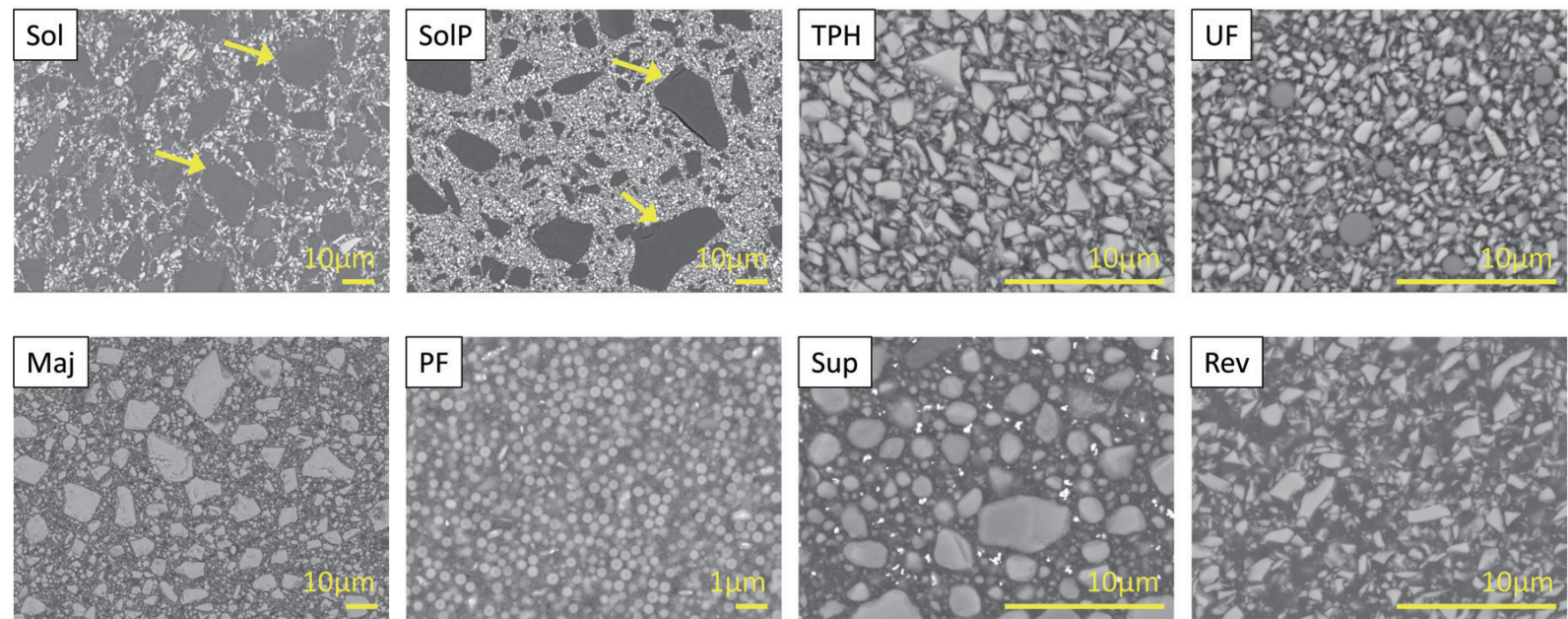

Fig. 4 BSE images of all specimens.

BSE images with various magnifications were used for image analysis. Yellow arrows indicate organic filler areas in Sol and SolP.

Table 2 Matrix content by the programming method, matrix volume ratio by the ash and pycnometer methods, and maximum temperature during polymerization

\begin{tabular}{lcccc}
\hline & $\begin{array}{c}\text { Matrix content }(\%) \\
\text { <programming method }>\end{array}$ & $\begin{array}{c}\text { Density of the fillers } \\
\text { (g/mL) } \\
\text { <Pycnometer method }>\end{array}$ & $\begin{array}{c}\text { Volume of organic } \\
\text { materials (\%) } \\
\text { <olume measurement } \\
\text { method }\end{array}$ & $\begin{array}{c}\text { Maximum temperature } \\
\text { during } \\
\text { polymerization }\left({ }^{\circ} \mathrm{C}\right)\end{array}$ \\
\hline Sol & $36.36(1.17)$ & $2.376(0.060)$ & $61.13(0.57)^{*}$ & $42.00(0.25)$ \\
SolP & $29.32(0.96)$ & $2.746(0.028)$ & $58.68(0.24)^{*}$ & $41.00(2.50)$ \\
TPH & $41.09(0.83)$ & $2.970(0.018)$ & $45.27(0.20)^{*}$ & $43.55(1.04)$ \\
UF & $54.34(1.74)$ & $2.840(0.037)$ & $52.89(0.39)$ & $50.92(2.32)$ \\
Maj & $52.74(1.08)$ & $2.597(0.037)$ & $52.38(0.45)$ & $51.25(3.49)$ \\
PF & $57.59(0.54)$ & $2.575(0.058)$ & $51.82(0.63)^{*}$ & $53.50(2.61)$ \\
Sup & $44.75(1.06)$ & $2.647(0.075)$ & $57.95(0.69)^{*}$ & $47.63(0.13)$ \\
Rev & $63.92(1.45)$ & $2.791(0.034)$ & $65.67(0.26)$ & $57.58(1.01)$ \\
\hline
\end{tabular}

Data are presented as the mean (standard deviation). An asterisk in a column indicates a significant difference in mean values between programming method and volume measurement method for the same specimen $(p<0.05)$.

specimens $\left(40^{\circ} \mathrm{C}\right)$ compared with the flowable-type specimens (range, $47.6-57.6^{\circ} \mathrm{C}$ ).

\section{DISCUSSION}

Various programming languages have long been used, including Fortran, ALGOL, Lisp, and COBOL $^{22)}$. Different languages have different uses, with Basic, C, $\mathrm{C}++$, and Java often used for application development, JavaScript and PHP often used for web development, and COBOL and others often used for financial system development. Some other examples are Perl, Ruby, and the beginner-oriented Scratch ${ }^{23)}$. More than 1,000 languages are in use today, among which Python is ranked in the top 5 most used programming languages ${ }^{15)}$, and its adoption is growing rapidly ${ }^{24}$. Python is a crossplatform programming language that provides powerful capabilities for working in Linux (including Ubuntu), Windows, Macintosh, and also Raspbian (for Raspberry $\mathrm{Pi}$ ). In light of the advantages and popularity of Python, in this research we used Python to implement one of the tools for automatic image analysis.

The image analysis developed in this study uses actual images obtained from cured RCs, and thus it can deal with rough structures, enabling information to be obtain about not only the amount of filler content, but also the morphology and type of filler. BSE images are known to provide compositional contrast corresponding 
to the number of BSEs, which monotonically increases with increasing average atomic number. The depth and width of imaging differ depending on the accelerating voltage of the electron beam and average atomic number (Z). As shown in Fig. 4, the structures are represented by varying densities and some of the images show a variety of constituent atoms, indicating that the depth that is imaged varies greatly depending on location ${ }^{25)}$. Thus, the BSE can be compared against secondary electron images obtained by scanning electron microscopy (SEM), which allows observation of the surface characteristics of materials. SEM depicts the surface structure to a depth of 5-50 nm. The BSE and SEM images of Maj are compared as follows (Fig. 5). In the BSE image, varying densities were observed, but a portion of them were hardly detectable using SEM (Fig. 5 , yellow arrows). These components visible in BSE but not SEM images were believed to be deep filler, and therefore should be classified as a matrix area at the surface. In addition, because the filler has an arbitrary cross-section and may often be imaged obliquely, the portion represented as a gradation (Fig. 5, green arrows) should similarly be classified as a matrix area at the surface. In fact, comparing Maj and Rev, which contain only inorganic fillers, the abundance ratio of organic materials obtained by the programming and volume measurement methods showed almost the same value. However, TPH, which contains a single type of filler, was found to have a matrix ratio about $4 \%$ smaller by the programming method compared with the volume measurement methods. Inorganic materials used in TPH include glass wool, silica, and $\mathrm{TiO}_{2}$. Their densities are $2.2-6.3,2.2$, and $4.23 \mathrm{~g} / \mathrm{cm}^{3}$, respectively. Glass wool has various compositions, such as barium glass, borosilicate glass, soda-lime glass, and flint glass. In the three specimens containing only inorganic fillers (Maj, $\mathrm{TPH}, \mathrm{Rev})$, component analysis of the fillers yielded the results shown in Table 3 . Compared with the other two specimens, TPH has a higher Ba content. Consequently, the brightness of the filler was higher on the BSE image of TPH compared with the other two specimens. In other words, the matrix ratio by programming may have been underestimated because the filler immediately below the matrix might be captured on BSE images. Although the constituent elements of fillers are beyond the scope of the present work, improving the programming method to take into account the effect of constituent elements on the characteristics of BSE images will be a topic of future work.

The K-means method used for automatic segmentation based on differences in color value between

Table 3 Field-emission electron probe micro analysis results

\begin{tabular}{ccc}
\hline Specimen & Element & Atom (\%) \\
\hline \multirow{4}{*}{ Maj } & $\mathrm{Al}$ & 4.28 \\
& $\mathrm{Si}$ & 22.65 \\
& $\mathrm{Ba}$ & 3.68 \\
& $\mathrm{~B}$ & 8.65 \\
$\mathrm{C}$ & 1.26 \\
& $\mathrm{O}$ & 59.48 \\
& $\mathrm{Al}$ & 3.5 \\
$\mathrm{TPH}$ & $\mathrm{Si}$ & 17.04 \\
& $\mathrm{Ba}$ & 2.74 \\
& $\mathrm{~B}$ & 8.99 \\
& $\mathrm{C}$ & 1.53 \\
& $\mathrm{O}$ & 57.73 \\
& & \\
& $\mathrm{Al}$ & 3.86 \\
& $\mathrm{Si}$ & 23.65 \\
& $\mathrm{Ba}$ & 4.24 \\
& $\mathrm{~B}$ & 3.8 \\
& $\mathrm{C}$ & 26.12 \\
& $\mathrm{O}$ & 46.8 \\
& &
\end{tabular}
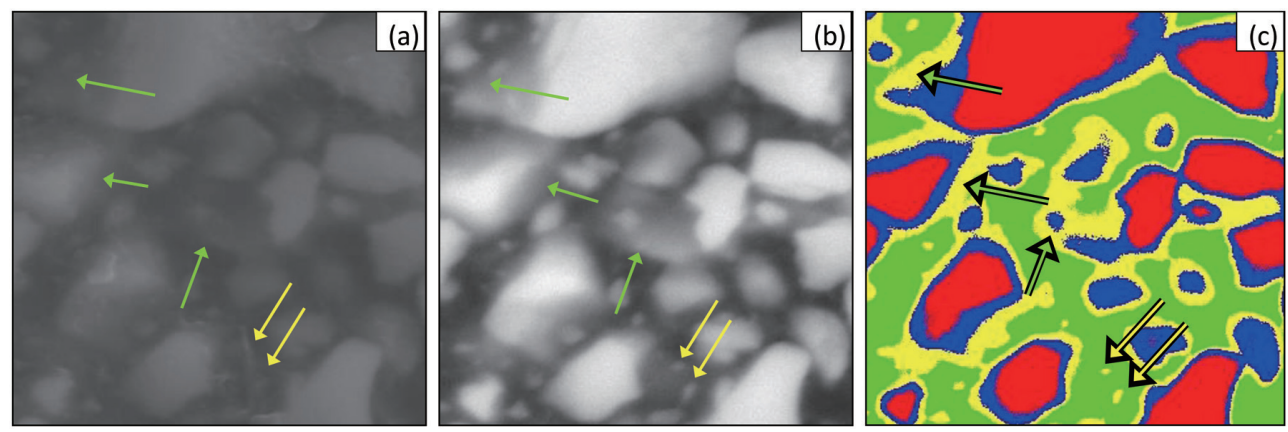

Fig. 5 Comparison between original SEM and BSE images and an image obtained using the K-means method.

(a) Original SEM image of Maj. Green arrows indicate filler not exposed at the surface as determined from the differing levels of gradation within and between filler and matrix. Yellow arrows indicate fillers that were hardly detectable in the SEM image. (b) Original BSE image of Maj. Green and yellow arrows indicate fillers that were detectable. (c) Image was obtained by the K-means method. Green and yellow areas indicate matrix, and red and blue areas indicate filler areas. 
filler and matrix is an unsupervised classification method. K-means clustering ${ }^{26)}$ is a method commonly used to automatically partition a data set into $\mathrm{k}$ groups. The data are separated into a set number of clusters, and a search is performed to find a way to segment the clusters resulting in optimal separation. This kind of clustering problem is very common in image recognition. This study implemented the K-means method, which is the simplest method. Other image processing methods such as the K-means++ method and fuzzy c-means method, but these were not examined in this study.

Magnified images were used for validation, and the Maj image is shown as an example in Fig. 5. The separated areas in red had the highest brightness in the original image, while the green areas represent the portion with the lowest brightness. Here, focusing on the small filler, the portions with the high brightness corresponding to filler at the surface are segmented in blue, and the faintly imaged small filler is segmented in yellow. In other words, the portions corresponding to the matrix of the sample are those represented in green and yellow. The other specimens were segmented using the same algorithm.

Using an area classification method, a segmentation program was created for fillers that are primarily organic material for which segmentation using the K-means method was not possible.

The Sol and SolP images in Fig. 4 show organic filler with a size greater than $20 \mu \mathrm{m}$ in the largest instances (yellow arrow), and also inorganic filler of two types with different atomic numbers. In the $10,000 \times$ images, the gaps between fillers have a size of about 20 pixels for Sol and about 10 pixels for SolP (unpublished data), which would respectively correspond to 2 pixels and 1 pixel in the $1,000 \times$ image used in the analysis. Therefore, when discriminating organic filler areas, the window size was set as 2 pixels. In addition, preprocessing involved separating the inorganic filler by image binarization. To do so, it was necessary to select a threshold that can perform classification with a filler gap of 1 or 2 pixels. By making a comparison at the four threshold levels of 120 , 130, 140, and 150, individual inorganic fillers could be distinguished, and the threshold level able to segment the matrix with an appropriate gap was found to be 140 (Fig. 6(a)). As shown in Figs. 6 (b and c), when the organic filler was segmented into continuous regions by applying the algorithm of Fig. 3 to an image binarized with a threshold of 140 , the result matched the number of pixels of filler represented by the yellow lines in the

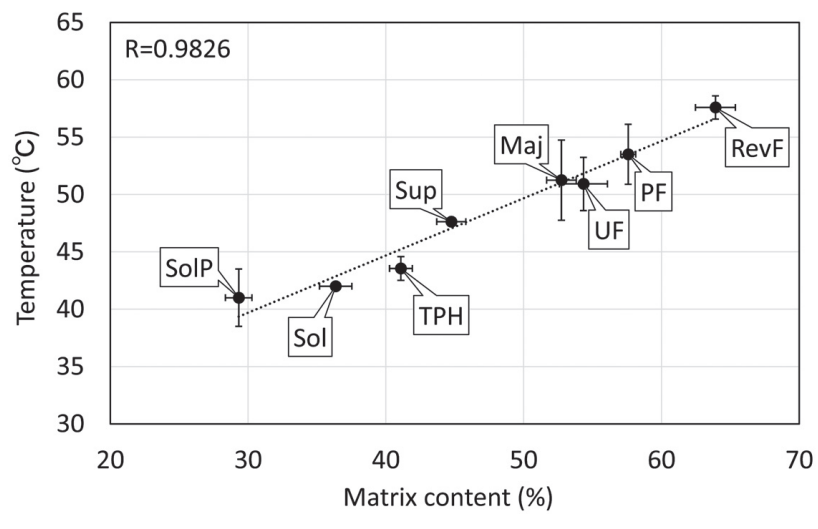

Fig. 7 Relationship between matrix content and maximum temperature during polymerization for each specimen.
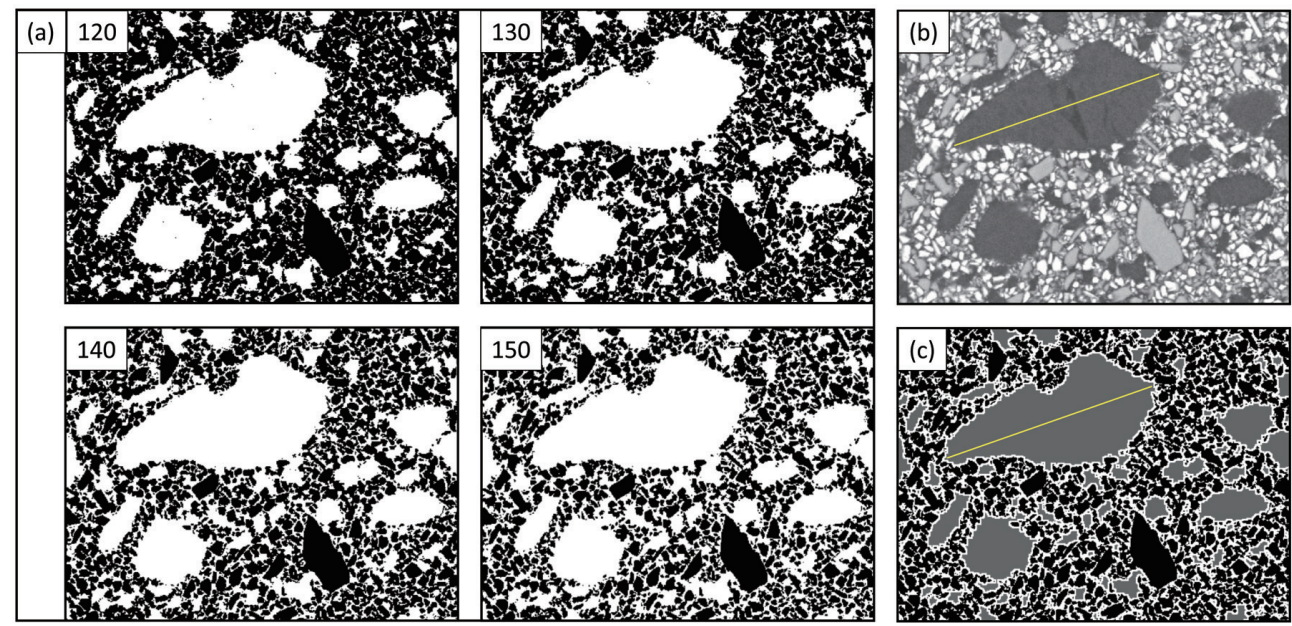

Fig. 6 Comparison with original images and image obtained by the area segmentation method.

(a) Comparison with each threshold steps. The number in the corner indicates the threshold value. (b) Original BSE image of SolP. (c) Image obtained by the area segmentation method. Yellow lines in (b) and (c) indicate the same length. Organic filler could be detected with the same size in both the original image and image processed by the area segmentation method. 
figure, confirming an accurate segmentation.

The heat of polymerization of $\mathrm{RCs}$ has been considered an issue in the clinical setting, and the amount of matrix greatly contributes to the temperature rise. An investigation of the relationship between the matrix weight percentages and the highest temperature reached during polymerization based on programming showed a strong correlation of $\mathrm{R}=0.9826$ (Fig. 7). The monomers used in RCs are mainly urethane dimethacrylate (UDMA; molecular weight 470.6), triethyleneglycol dimethacrylate (TEGDMA; molecular weight 286.3), and bisphenol A-glycidyl methacrylate (Bis-GMA; molecular weight 512.6), all of which are polyfunctional monomers. The polymerization reaction is exothermic and generates heat due to the higher amount of energy contained in double bonds $(636 \mathrm{~kJ} / \mathrm{mol})$ than in single bonds $(386 \mathrm{~kJ} /$ mol). The lower the number of double bonds relative to the molecular weight, the less heat is generated during polymerization, so monomers with a large molecular weight have also found use in recent years ${ }^{27)}$. For this reason, some amount of error is expected in the highest temperature reached during polymerization and the calculation of the matrix abundance ratio according to the images obtained in our experiments.

However, this study enabled images to be used for segmentation of organic composite fillers, fillers with nano-scale microstructures, and fillers made from the same components as the matrix, which cannot be distinguished by density variations. Accordingly, programming is a technique that can by itself provide a variety of functions, and it is becoming necessary to learn such techniques as computer technology advances $^{28)}$. Since programming can perform analysis without human error and can apply identical criteria, accurate data can be easily obtained. Programming can be applied not only in structural analysis of the $\mathrm{RCs}$ used in this experiment, but also in a wide range of fields, including measurement of the size of zirconia particles, analysis of metallographic structure, and cell counting in biochemistry. In fact, Hori et al. ${ }^{29)}$ reported the determination of polymer particle size by a programming method. These flexible approaches are used frequently not only in research but also in the clinical setting for diagnosis, and so programming has a broad scope of application. The techniques used in this study are considered to be a very effective tool.

\section{CONCLUSION}

A new method was constructed to measure the matrix ratio of $\mathrm{RCs}$ using $\mathrm{BSE}$ images without human intervention. The K-means method could be used for segmentation of only surface-exposed filler by unsupervised classification from BSE images that also depict the deeper structure. In cases where the matrix and organic fillers have the same color values, the area segmentation method was applied. The results for matrix ratios obtained by both methods were strongly correlated with the maximum temperature during the polymerization reaction $(\mathrm{R}=0.9826)$. These programming technologies can be applied not only in structural analysis of RCs but also in other fields such as diagnosis in the clinical setting.

\section{REFERENCES}

1) Santini A, Watterson C, Miletic V. Temperature rise within the pulp chamber during composite resin polymerisation using three different light sources. Open Dent J 2008; 2: 137141.

2) Loney RW, Price RBT. Temperature transmission of highoutput light-curing units through dentin. Oper Dent 2001; 26: 516-520.

3) Hori M, Fujimoto K, Asakura M, Nagase Y, Mieki A, Kawai T. Measurement of exothermic heat released during polymerization of a light-curing composite resin: Comparison of light irradiation modes. Dent Mater J 2019; 38: 646-653.

4) International Organization for Standardization, Dentistry - polymer-based restorative materials, ISO 4049, Fourth edition, 2009

5) Malkondu Ö, Yurdagüven H, Say EC, Kazazoğlu E, Soyman M. Effect of bleaching on microhardness of esthetic restorative materials. Oper Dent 2011; 36: 177-186.

6) Berger SB, Palialol ARM, Cavalli V, Giannini M. Surface roughness and staining susceptibility of composite resins after finishing and polishing. J Esthet Restor Dent 2011; 23: 34- 45.

7) Schmitt VL, Puppin-Rontani RM, Naufel FS, Nahsan FPS, Sinhoreti MAC, Baseggio W. Effect of the polishing procedures on color stability and surface roughness of composite resins. ISRN Dent 2011; 617672.

8) Leprince J, Palin WM, Mullier T, Devaux J, Vreven J, Leloup G. Investigating filler morphology and mechanical properties of new low-shrinkage resin composite types. J Oral Rehabil 2010; 37: 364-376.

9) Rastelli ANS, Jacomassi DP, Faloni APS, Queiroz TP, Rojas SS, Bernardi MIB, et al. The Filler content of the dental composite resins and their influence on different properties. Microsc Res Tech 2012; 75: 758-765.

10) Chunga SM, Yapa AUJ, Kohb WK, Tsaic KT, Lim CT. Measurement of Poisson's ratio of dental composite restorative materials. Biomaterials 2004; 25: 2455-2460.

11) Lee JH, Um CM, Lee IB. Rheological properties of resin composites according to variations in monomer and filler composition. Dent Mater 2006; 22: 515-526.

12) Masouras K, Silikas N, Watts DC. Correlation of filler content and elastic properties of resin-composites. Dent Mater 2008; 24: 932-939.

13) Schneider CA, Rasband WS, Eliceiri KW. NIH Image to ImageJ: 25 years of image analysis. Nat Methods 2012; 9: 671-675.

14) Chen H, Ding CX. Nanostructured zirconia coating prepared by atmospheric plasma spraying. Surf Coat Technol 2002; 150: 31-36.

15) Cass S. The 2015 top ten programming languages. IEEE Spectr 2015.

16) Dobesova Z. Programming language Python for data processing. Int Mech Eng Congress Expo 2011; 6: 4866-4869.

17) Kaifosh P, Zaremba JD, Danielson NB, Losonczy A. SIMA: Python software for analysis of dynamic fluorescence imaging data. Front Neuroinform 2014; 8: Article80.

18) KnudsenEB, Sørensen HO, Wright JP, Goret G, Kieffer J. FabIO: easy access to two-dimensional X-ray detector images in Python. J Appl Cryst 2013; 46: 537-539.

19) Tavazoie S, Hughes JD, Campbell MJ, Cho RJ, Church GM. Systematic determination of genetic network architecture. Nat Genet 1999; 22: 281-285.

20) International Organization for Standardization, Textile- 
glass-reinforced plastics. Prepregs, moulding compounds and laminates. Determination of the textile glass and mineral-filler content. Calcination methods, ISO 1172, 2nd edition, 1996.

21) Dewaele M, Truffier-Boutry D, Devaux J, Leloup G. Volume contraction in photocured dental resins: The shrinkageconversion relationship revisited. Dent Mater 2006; 22: 359365 .

22) Wexelblat RL. History of programming languages. Academic Press, 1981.

23) Maloney J, Resnick M, Rusk N, Silverman B, Eastmond E. The scratch programming language and environment. ACM Transactions on Computing Education 2010; 10: Article16.

24) Simon, Mason R, Crick T, Davenport JH, Murphy E. Language choice in introductory programming courses at Australasian and UK universities. Proceedings of the 49th ACM Technical Symposium on Computer Science Education 2018; 852-857.

25) Muscente $\mathrm{AD}$, Xiao S. Resolving three-dimensional and subsurficial features of carbonaceous compressions and shelly fossils using backscattered electron scanning electron microscopy (BSE-SEM). Palaios 2015; 30: 462-481.

26) MacQueen J. Some methods for classification and analysis of multivariate observations. Fifth Berkeley Symp Math Statist Prob 1967: 281-297.

27) Yamazaki LC, Moraes AGD, Barros M, Lewis S, Francci C, Stansbury JW, et al. Polymerization development of "lowshrink" resin composites: Reaction kinetics, polymerization stress and quality of network. Dent Mater 2013; 29: e169e179.

28) Gu L, Yan N, Xiu Y. Discussion on teaching methods and choice of programming language on software engineering major. Asia-Pacific Engineering and Technology Conference 2017: 1681-1686.

29) Hori M, Hori T, Sekine H, Mieki A, Fujimoto K, Kawai T. Shrinkage characteristics of a novel lower contractile acrylic pattern resin. Dent Mater J 2019; 38: 900-908. 